\section{Safe and effective sedation}

\author{
David Craig \\ Chairman, The Independent Expert Group on \\ Training Standards for Sedation in Dentistry
}

Send your comments to the

Editor-in-Chief,

British Dental Journal

64 Wimpole Street,

London

W1G 8YS

Email bdj@bda.org

Dr Craig may be contacted at david.craig@kcl.ac.uk
In 2007 the Standing Committee on Sedation for Dentistry at the Faculty of Dental Surgery, RCS Eng published guidance on the use of 'alternative' conscious sedation drugs and techniques. ${ }^{1}$ Since then a number of expert groups have sought to advance training by developing a syllabus. The Intercollegiate Advisory Committee for Sedation in Dentistry (IACSD) reached agreement on the majority of issues relating to alternative adult techniques and guidelines on sedated-related CPD but was disbanded before the work was completed. However, a group comprising many previous members of the IACSD elected to continue the work as an 'independent expert group'. The Independent Expert Group on Training Standards for Sedation in Dentistry (IEGTSSD) has now finalised both the adult and paediatric syllabi and also CPD recommendations. Publication of all these documents was announced at the Society for the Advancement in Anaesthesia in Dentistry's (SAAD) Annual Symposium held at the Royal Society for Medicine on 24 September 2011.

\section{BASIC AND ADVANCED TECHNIQUES}

Both the IACSD and the IEGTSSD recognised that the majority of conscious sedation dental procedures involve the use of a single drug - either nitrous oxide with oxygen or midazolam and so these have now been designated 'basic' techniques. These highly effective and safe techniques form the basis of undergraduate teaching in UK dental schools and also on SAAD's National Course in Conscious Sedation for Dentistry.

Conscious sedation involving other drugs and some modes of administration are now designated 'advanced' (rather than 'alternative'). Advanced conscious sedation techniques are far less widely used and more complex to administer than the basic techniques. In order to ensure essential standards of quality and safety, it is important that all dental and medical practitioners administering advanced sedation are trained to the same high standard and meet a pre-requisite set of competencies. Many of the drugs that are used for conscious sedation are also used to produce general anaesthesia and thus require specific training in their administration. At present, postgraduate training opportunities for advanced conscious sedation techniques are scant.

The IEGTSSD considers that continuing access to a range of effective and safe sedation techniques is necessary in order to provide appropriate care for patients who are unable to tolerate treatment without sedation and also to avoid the unnecessary use of general anaesthesia. Irrespective of where treatment is carried out, all providers of advanced conscious sedation have a responsibility to ensure full compliance with contemporary standards. All current guidance is based on the work of sequential expert committees and expert working groups representing stakeholders who have taken care to ensure that changes to earlier guidance have been based on published evidence and audit data rather than emotive and unsubstantiated opinion.

The IEGTSSD's syllabi for adult and paediatric advanced conscious sedation techniques in dentistry seek to formalise training for those practitioners who wish to commence the provision of advanced sedation and to facilitate the development of practical training programmes. The syllabi describe the requirements for entry to training, the training objectives, the syllabus, models of learning, supervision and assessment. They define the knowledge, skills, attitudes and behaviours required of dental and medical practitioners wishing to undergo training in advanced sedation techniques for dentistry. However, IEGTSSD acknowledges that some practitioners currently providing advanced conscious sedation may have received appropriate training by a different route.

The adult and paediatric syllabi are based on recommendations contained in three publications. ${ }^{1-3}$ All these documents have been accepted by healthcare professions, however, none provides a training syllabus for either basic or advanced conscious sedation techniques.

IEGTSSD's Guide to maintaining professional standards in conscious sedation for dentistry makes recommendations on sedation-related CPD. It was written in response to the large number of queries received by SAAD relating to the amount and nature CPD required by sedationists. The document contains detailed guidance on the amount of verifiable CPD, non-verifiable CPD, management of complications, clinical audit, recording adverse events and regular checks of clinical facilities and team training.

IEGTSSD and SAAD hope that sedationists will find these three documents helpful - a valuable guide to continuing dentistry's excellent record of providing safe and effective pain and anxiety management for our patients. The documents can be downloaded from www.saad.org uk/documents.

1. Standing Committee on Sedation for Dentistry. Standards for conscious sedation in dentistry: alternative techniques. London: RCS(Rng)/RCoA, 2007. http://www. saad.org.uk/files/documents/scsdat-2007.pdf

2. Standing Dental Advisory Committee. Conscious sedation in the provision of dental care. London: Department of Health, 2003. http://www.dh.gov.uk/ prod_consum_dh/groups/dh_digitalassets/@dh/@en/documents/digitalasset/ dh 4074705.pdf

3. National Institute for Health and Clinical Excellence. Sedation in children and young people. CG112. London: NICE, 2010. http://guidance.nice.org.uk/CG112

DOI: 10.1038/sj.bdj.2011.873 